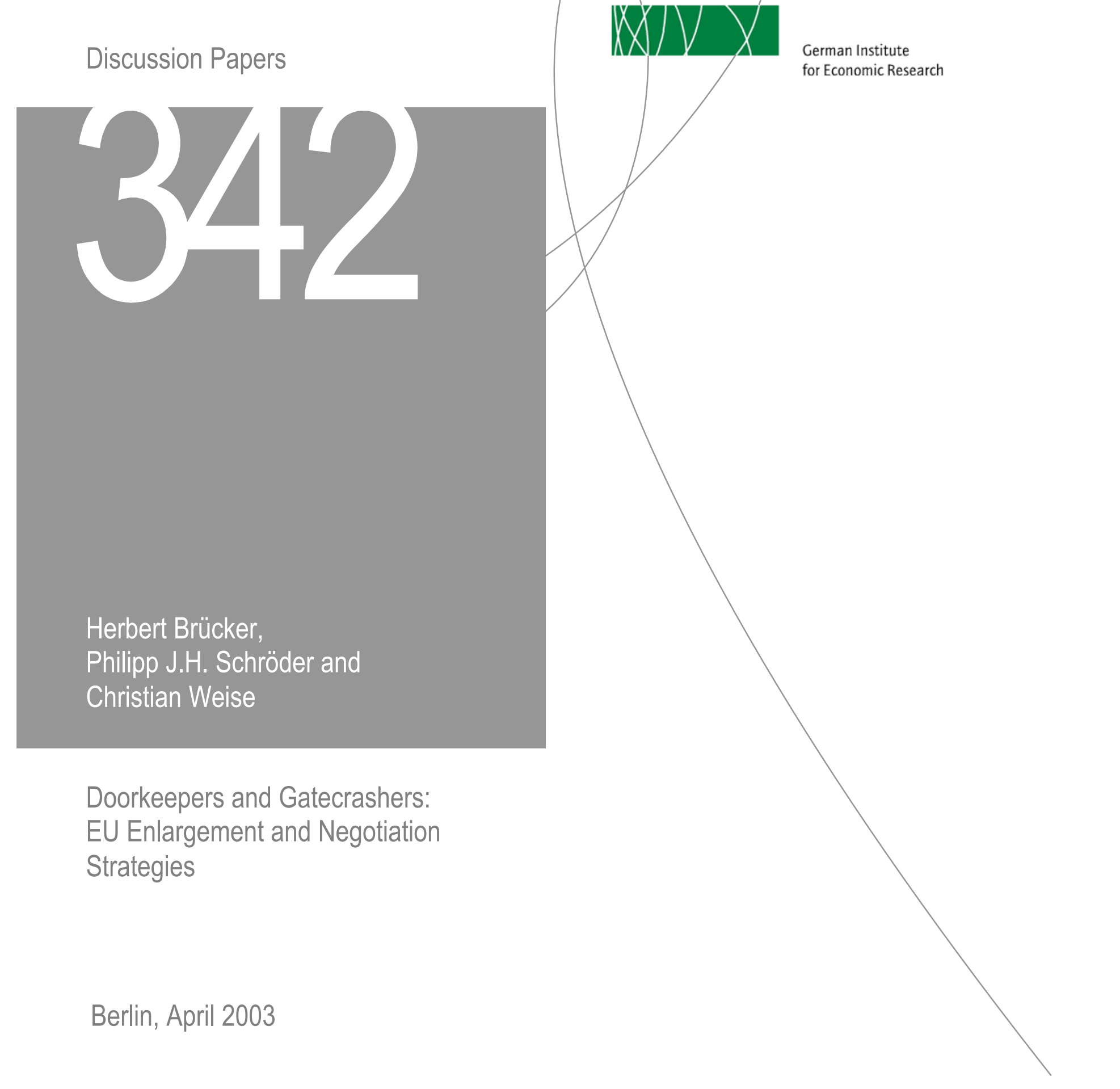


Opinions expressed in this paper are those of the author and do not necessarily reflect views of the Institute.

\section{DIW Berlin}

\section{German Institute}

for Economic Research

Königin-Luise-Str. 5

14195 Berlin,

Germany

Phone +49-30-897 89-0

Fax +49-30-897 89-200

www.diw.de

ISSN 1619-4535 


\title{
Doorkeepers and Gatecrashers: EU Enlargement and Negotiation Strategies
}

\author{
Herbert Brücker Philipp J.H. Schröder* \\ Christian Weise
}

April 2003

\begin{abstract}
This paper discusses the eastward enlargement process of the EU in the framework of a simple war of attrition bargaining game. Both players - the existing EU members and the applicants - benefit from enlargement, yet for the applicants reform to the acquis is costly, while the EU prefers substantially reformed candidates. A waiting game unfolds. Within this framework the present enlargement round is analyzed and policy results are deduced. For example, it is shown that delegating the evaluation of applicants to a third party, compensating applicants for their reform efforts or increasing the benefits for new members are all effective negotiation strategies for the EU that have been applied in the process.
\end{abstract}

Key Words: EU enlargement, eastern enlargement, bargaining, reform, war of attrition.

*All authors: DIW Berlin - German Institute for Economic Research. Corresponding author: Philipp J.H. Schröder, DIW Berlin, Königin-Luise-Straße 5, 14195 Berlin, Germany, Tel.: +49 30 89789-692, Fax:+49 30 89789-108, e-mail: pschroeder@diw.de. 


\section{Introduction}

The eastward enlargement of the European Union promises vast benefits for the involved parties. Yet, within the enlargement process itself, tough bargaining has taken place over financing, free mobility of labor, market access and the implementation of the acquis communautaire in general. These two faces of eastward enlargement come as no surprise, because although the overall benefits seem patently obvious, the costs and benefit of this historical step are distributed unevenly (see e.g. Baldwin et al. (1997), Boeri et al. (2000), Weise et al. (2001)). This paper discusses the enlargement bargaining process within the simple framework of a war of attrition. Both parties - the existing EU members and the applicant countries - benefit from enlargement. For the applicants full compliance with the acquis communautaire is costly, hence they will attempt to achieve membership on less strict terms. The present EU members, however, benefit most from admitting substantially reformed candidates, but would rather accept partially reformed countries than postpone enlargement indefinitely. A waiting game unfolds where the players will attempt to send certain signals as to their preferences, delegate decisions to 'tough' third parties, or try to display patience and indifference with respect to the final outcome, thus attempting to force their opponent into compliance.

After the collapse of the old economic and political system in eastern Europe it became evident that membership in the EU was, at least, a mid-term objective for many countries of the region. Since previous enlargements were of a smaller scale, the EU - unprepared to handle immediate applications developed a formalised enlargement process. Following the initial EuropeAgreements, which dealt with political, economic and cultural co-operation and promotion of free trade, the EU clarified the enlargement conditions in the Copenhagen Criteria of 1993. These conditions included items such as compliance with the aims of a political and a monetary union, existence of a functioning market economy and, in general, an implementation of the acquis communautaire. These conditions were then followed up by regular screenings conducted by the Commission, which ultimately evolved into the actual enlargement negotiations (starting with the first wave in 1998) that have now been concluded for the first ten applicants.

As the formal framework for our analysis of this ten year enlargement process, we use a war of attrition waiting game. This game is won by the player willing to wait the longest for his favorite outcome to materialise. The applicant country attempts to be admitted with an only partially implemented acquis communautaire or otherwise curtailed reforms in order to minimize the costs of reform and adjustment. The EU endeavors to pressure 
the prospective applicants into complete and substantial reform in order to maximise the benefits from enlargement. Other papers employing a similar approach - a war of attrition setting applied to national or international bargaining situations over economic reforms - are those of Alesina and Drazen (1991), who examine fiscal stabilisation; Perotti (1998), who studies financial sector reform in transition economies; and Heinemann (2000), who discusses the strategic effects of creating the EMU.

While the structure and dynamics of the accession process have been the central focus in the political science literature ${ }^{1}$, the vast majority of the economic literature ${ }^{2}$ on EU eastward enlargement focuses on the economic costs and benefits. The present paper combines elements of both approaches. We categorise the bargaining process as a waiting game. Within this framework we can study various bargaining strategies and episodes that the EU and applicants have employed during the past ten years. In doing so we are able to evaluate a priori the entry conditions of different types of candidates. For example, those applicants showing the most promise in terms of benefits for the existing members will enter on weaker conditions than applicants with more at stake, i.e. applicants that have more to gain from membership. Or countries where the public is tending to show less support for EU-membership will - within our framework - be able to enter on more favorable (weaker reform) terms. More importantly, within our framework, several of the actually employed bargaining devices of the incumbent EU member countries, turn out to be efficient negotiation strategies. Examples include the strategy of committing and out-sourcing the formal evaluation of the candidates reform status (i.e. the Copenhagen Criteria) to the Commission, and that of evaluating the progress of each country individually without closing the door (i.e. the 'Regatta'-model). These are sensible devices with which the existing EU members can achieve their most favorite outcome in the enlargement bargaining game.

The paper is structured as follows. Section 2 introduces a simple war of attrition game as a framework for our analysis. Section 3 applies this conceptual framework to an analysis of the past ten years of the enlargement process. Section 4 concludes the paper.

\footnotetext{
${ }^{1}$ See for example Schimmelfennig and Sedelmeier (2002), Mattli and Plumper (2002), Grabbe (2001) and (2002) but also - from a practicioners point of view - Mayhew (2000).

${ }^{2}$ See for example Baldwin et al. (1997), Breuss (1999), Kohler (2000), or, for the case of the costs and benefits of enlarging the CAP, Josling et al. (1998) and Tangermann and Banse (2000).
} 


\section{A simple framework}

Consider an EU applicant country, $A$, and the existing EU members, $E$, that play a war of attrition type game to obtain enlargement. The incumbent EU members can unilaterally decide on admitting a new member (enlargement occurs). $E$ has - in some initial step - outlined the reform requirements for new members but is unable to enforce these reforms directly except by postponing membership. The applicant decides to implement or not to implement the acquis (required reforms). Both parties, $A$ and $E$, benefit from enlargement. In the status quo - no membership and no reform - the payoffs for both players are normalised to zero. Any change from the status quo results in the following present value payoffs, (which may or may not be known to the parties): The gains to the existing EU members from admitting a new country are $\alpha$. The total costs from allowing an incompletely reformed country to enter are given by $\sigma$. The gains to the applicant, $A$, from the country becoming an EU member are $\beta$. The present value of all costs that the applicant faces when implementing complete reform in compliance with the entry requirements - net of the benefits that may stem from these reforms - is $\tau$. All parameters $\alpha, \sigma, \beta, \tau>0$. The payoff structure is summarised in Table 1 .

\begin{tabular}{ll|cc} 
& & \multicolumn{2}{|c}{ EU } \\
& & enlarge & do not enlarge \\
\hline \multirow{2}{*}{ Applicant } & & $\beta-\tau, \alpha$ & $-\tau, 0$ \\
& do not fulfill & $\beta, \alpha-\sigma$ & 0,0
\end{tabular}

Table 1: The enlargement game (payoffs: $A, E$ )

The sequence of the game is as follows:

- Step 0: E states membership requirements and opens enlargement round.

- Step 1: $A$ choose to fulfill or not to fulfill the requirements.

- Step 2: $E$ chooses to admit or postpone enlargement.

- Step 3: If enlargement is postponed the game is repeated with probability $1-\phi$ or ends with probability $\phi$ (payoff zero). If enlargement occurs, payoffs are realised and the game ends.

Thus the game ends - possibly after some periods of delay - with either EU membership or with a "closing the door" situation, i.e. the risk that there 
will be no further enlargement rounds such that the status quo is maintained indefinitely (do not fulfill, do not enlarge). The probability $\phi(0<\phi<1)$ will be discussed as a policy parameter of the incumbent EU members. From the sequence and payoffs of this game it immediately follows that once the applicant has implemented the reform requirements, the EU's best strategy is to proceed with enlargement; thus the situation (step one: fulfill step two do not enlarge) is not an equilibrium. In fact in the one-shot game with $\alpha>\sigma$ enlarge is E's dominant strategy and accordingly, the game would end in the (do not fulfill, enlargement) equilibrium, regardless of $\beta$ and $\tau$. In the remainder we assume $\alpha>\sigma$ and $\beta>\tau .{ }^{3}$

The dynamics of this setup emerge in the repeated version, where both players have the power to end the game: the applicant by following through with reforms and the EU by admitting a non-reformed applicant. Yet by not reforming and postponing, the players may choose to wait and delay the game in the hope that the other player will subsequently give up, thus allowing their own favorite outcome to materialise. The EU's favorite outcome is to admit a reformed country (payoff $\alpha$ ) while the applicants' favorite outcome is to obtain membership without fulfilling the requirements (payoff $\beta$ ). But waiting is costly. Players discount the future. Payoffs realised in subsequent periods are discounted at the rate of time preference $\rho_{j}, j=A, E$ for the applicant and the existing EU members respectively. This gives a discount factor of $\frac{1-\phi}{1+\rho_{j}}, j=A, E$. Even though waiting is costly for both players, they are each willing to wait a certain period of time hoping for the other player to give up. The war of attrition is won by the player willing to wait the longest for his favorite outcome to occur (see Bliss and Nalebuff, 1984).

\section{Maximum waiting times}

Since the war of attrition is won by the player willing to forego his winning payoff longer than his opponent, the maximum waiting times must be established. But even though agents are willing to wait there need not be any delay. In effect, given the use of pure strategies only and a situation of complete information, there will be no substantial delay. Rather, the player who realises that he will lose eventually will give up right away (harvesting his losing payoff) instead of enduring any delay and staying in the status quo, (see Hendricks et al., 1988). On the other hand, in settings of incomplete information, the game will feature some delay (Alesina and Drazen, 1991) until the more patient agent has established his willingness to wait. what is

\footnotetext{
${ }^{3}$ In a one-shot version with $\alpha<\sigma$ and $\tau<\beta$ the game would end in the (do fulfill, enlarge) equilibrium, while with $\alpha<\sigma$ and $\tau>\beta$ the game would persist in the status quo (do not fulfill, do not enlarge).
} 
important for our analysis is to examine how the maximum waiting times of the EU and the applicant country are affected by the various parameters of the model. The maximum waiting time, $\bar{t}_{E}$, of the EU is defined by equating the value of winning the bargaining game in the future and the value of giving up immediately:

$$
\alpha\left(\frac{1-\phi}{1+\rho_{E}}\right)^{\bar{t}_{E}}=\alpha-\sigma .
$$

The right-hand side is simply the present value of giving up right away, i.e. permitting an un-reformed applicant into the EU. On the left-hand side, we have the present value to the EU of the applicant country giving in and fulfilling the reform requirements (with membership resulting) at time $\bar{t}_{E}$. From (1) the maximum waiting time of the EU is given by:

$$
\bar{t}_{E}=\ln \left(\frac{\alpha-\sigma}{\alpha}\right) \ln \left(\frac{1-\phi}{1+\rho_{E}}\right)^{-1} \text {. }
$$

Fully parallel, the problem of the applicant country can be stated by equating the favorite outcome at time $\bar{t}_{A}$ with giving up immediately:

$$
\beta\left(\frac{1-\phi}{1+\rho_{A}}\right)^{\bar{t}_{A}}=\beta-\tau .
$$

The left-hand side is the value of winning at time $\bar{t}_{A}$, while the right-hand side is the value of giving up today, i.e. fulfilling the reform requirements and becoming an EU member immediately. From (3) the maximum waiting time of an applicant is:

$$
\bar{t}_{A}=\ln \left(\frac{\beta-\tau}{\beta}\right) \ln \left(\frac{1-\phi}{1+\rho_{A}}\right)^{-1} .
$$

Due to the sequential nature of the game, when the applicant country plays 'tough' i.e. does not fulfill the reform requirements, then the EU, if it decides to postpone the enlargement for the present round (punish the applicant), can at best achieve its favorite outcome (admittance of a reformed country) in the next enlargement round. Formally we can state:

Lemma 1. The EU wins the enlargement bargaining if $\bar{t}_{E}>\bar{t}_{A}+1$, resulting in the applicant fulfilling the reform requirements and enlargement occurring.

The reasoning of lemma (1) is the common intuition behind the war of attrition whereby the player that can establish that he is willing to wait longer 
than his opponent [either by demonstrating his ability to wait (incomplete information) or because his ability to wait is known (complete information)] wins the game. He does so because the other player - after recognizing the other's superior ability to hold out longer - maximises his payoff by giving up right away (see Bliss and Nalebuff (1984), Alesina and Drazen (1991), Hendricks et al. (1988)).

\section{EU and applicant parameters}

When differentiating $\bar{t}_{E}$ and $\bar{t}_{A}$ with respect to the gain, cost and time preference parameters of the two players, the standard war of attrition results are obtained. Formally, for the maximum waiting time of the EU we can state:

Proposition 1. The EU's maximum waiting time $\bar{t}_{E}$ increases, i.e. the EU's chances of winning - the applicant country implementing the reform requirements and joining the EU - increase, when ceteris paribus:

i) the EU's benefits from EU enlargement, $\alpha$, decrease

ii) the EU's costs of admitting un-reformed countries, $\sigma$, increase

iii) the EU becomes more patient, i.e. $\rho_{E}$ decreases

The derivatives of $\bar{t}_{E}$ are presented in Appendix A.1. What proposition 1 says follows a clear intuition. If the $\mathrm{EU}$ is too eager to admit an applicant into the club, it reduces its chances of being able to pressure for complete fulfillment of the entry requirements. On the other hand, as the costs of including members that are only partially reformed increase, the EU has a stronger standing in the bargaining. Finally, patience - as always in the war of attrition - is a good strategy for winning the game.

Next, the maximum waiting time of the applicant country can be examined in much the same fashion. The following parallel results can be stated:

Proposition 2. The applicant's maximum waiting time $\bar{t}_{A}$ increases, i.e. the applicant's chances of winning - the EU admitting the applicant without having fulfilled the reform requirements - increase, when ceteris paribus:

i) the applicant's benefits from EU membership, $\beta$, decrease

ii) the applicant's costs of implementing the required reforms, $\tau$, increase

iii) the applicant becomes more patient, i.e. $\rho_{A}$ decreases 
The derivatives of $\bar{t}_{A}$ are presented in Appendix A.2. Proposition 2 also displays a clear intuition. For example, applicants that benefit significantly from EU membership can be more easily forced to fulfill all the reform requirements set out. From propositions 1 and 2 and the framework in general, we can deduce the following policy implications:

\section{Policy implications - Part 1}

The incumbent EU member states can strengthen their position in enlargement bargaining by

- delegating the evaluation of the reform progress and the decision on entry to a third party,

- displaying patience (and not setting a first-enlargement-wave deadline),

- emphasising the costs to the EU of admitting un-reformed countries,

- downplaying the benefits of enlargement for the existing EU members,

- dampening and/or compensating the costs that implementation of reform requirements imposes on the applicants,

- fostering and/or increasing the benefits for new members,

An applicant can strengthen its position in enlargement bargaining by

- downplaying the benefits from and the interest in EU membership,

- exaggerating the costs that the required reforms and demands of the EU cause,

- displaying patience (and insisting on a first-enlargement-wave deadline prior to $\left.\bar{t}_{E}\right)$.

\section{Extension: effects of closing the door}

Increasing or decreasing the probability that a postponed game is terminated, i.e. altering the closing-the-door probability $\phi$, affects both $\bar{t}_{E}$ and $\bar{t}_{A}$. In order to make further inferences, one can summarise the basic reasoning of lemma 1 by formulating the function $f=\bar{t}_{E}-\bar{t}_{A}-1$, which for positive values says that the EU is winning, and for negative values that the applicant is winning. Plugging in (2) and (4) and rewriting gives:

$$
f=\frac{\ln \left(\frac{\alpha-\sigma}{\alpha}\right)}{\ln \left(\frac{1-\phi}{1+\rho_{E}}\right)}+\frac{\ln \left(\frac{\beta}{\beta-\tau}\right)}{\ln \left(\frac{1-\phi}{1+\rho_{A}}\right)}-1
$$

Under an assumption of equal rates of time preference $\left(\rho_{E}=\rho_{A}=\rho\right)$ the win-lose ratios $\frac{\alpha}{\alpha-\sigma}$ and $\frac{\beta}{\beta-\tau}$, become decisive for the sign of $\frac{\partial f}{\partial \phi}$. In particular 
the following result is obtained:

Proposition 3. An increase in the probability that the enlargement process is closed, i.e. increasing $\phi$

i) improves the bargaining position of the EU if the EU's win-lose ratio is smaller than the applicant's win-lose ratio, i.e. the EU has less at stake. Namely, $\frac{\partial f}{\partial \phi}>0$ if $\frac{\alpha}{\alpha-\sigma}<\frac{\beta}{\beta-\tau}$.

ii) worsens the bargaining position of the EU if the EU's win-lose ratio is larger than the applicant's win-lose ratio, i.e. the EU has more at stake. Namely, $\frac{\partial f}{\partial \phi}<0$ if $\frac{\alpha}{\alpha-\sigma}>\frac{\beta}{\beta-\tau}$.

For proof of this proposition see appendix A.3. The probability of closing the door, $\phi$, affects both the EU's and the applicant's willingness to wait. Hence, the intuitively expected case, where an increased probability of closing the door helps to discipline future members into compliance does not hold for all constellations. In fact, if the EU haqd too much at stake (for example, the win-lose ratio increases once the costs of admitting unprepared agents increases, $\sigma$ increases), then limiting the number of enlargement rounds may harm the EU's position. Consequently, following proposition 1 and the derived policy implications, this implies that a strategy of claiming high costs from admitting unprepared members (which implies a high EU win-lose ratio) can only be a good negotiation strategy in combination with an open (low $\phi$ ) enlargement process. The inverse reasoning is also true when the applicant has much at stake (for example, the applicant's win-lose ratio grows as the cost of enlargement, $\tau$, increases), then paradoxically a reduction in the number of future round (lower $\phi$ ) improves the applicant's bargaining position. Still in general, since it is reasonable to assume that the applicant countries have more at stake than the existing EU members, our results in proposition 3 show that a threat of closing the door does indeed improve the position of the EU.

From the conceivable changes to the win-lose ratios and under the assumption that the probability of terminating the enlargement process is a decision parameter of the incumbent EU members, some further policy implications can be derived: 


\section{Policy implications - Part 2}

The following combinations of policies strengthen the EU's position in enlargement bargaining :

- Claiming large benefits from enlargement (high $\alpha$ ) and limiting the number of enlargement rounds.

- Claiming high costs from admitting un-reformed applicants (high $\sigma$ ) and increasing the number of enlargement rounds.

- Increasing the benefits of membership for new members (high $\beta$ ) and limiting the number of enlargement rounds.

- Imposing more costly reform requirements (high $\tau$ ) and increasing the number of enlargement rounds.

\section{The enlargement process - strategies and results}

In the following, we will analyse the actual enlargement process in the light of our war of attrition scenario using the policy implications derived in section 2 . As we will see, the actual development of the enlargement process throughout the 90s corresponds nicely to the general framework of our model. However, some of its limitations are also shown.

\section{Main steps of the enlargement process}

Soon after the collapse of the old economic and political system in the COMECON, the Central and Eastern European Countries (CEECs) began to make closer relations with the European Union a key focus of their political endeavors. Membership in the EU quickly became at least a mid-term objective of these countries. Until then, several enlargements of the EU had already taken place - all of them of relatively small scope and under a quite general legal framework. ${ }^{4}$ Thus, the EU assessed itself as being not fully prepared to handle immediate applications of all possible would-be members. The

\footnotetext{
${ }^{4}$ In principle, any European country could apply for EU membership. The basic treaty of the European Economic Community did not contain specific conditions. Only the Amsterdam treaty revision of October 1997 defined some explicit requirements. Article 49 of the EU-Treaty states that a European country might apply for membership in the EU under the condition that it respects the principles of liberty, democracy, human rights and basic freedoms as well as the rule of law.
} 
perceptions of the benefits of $n$ eventual EU membership for both sides and of the conditions that might be attached to this were very unclear, or - in terms of our model - the decisive parameters $(\alpha, \beta, \sigma$ and $\tau)$ were almost completely unknown.

However, the structure of the problem as outlined in the previous section was clear. Immediate accession was out of the question. In line with the recommendations of the war of attrition framework, the EU pointed out the problems of a premature membership of ill-prepared transition countries and it showed patience. A step-by-step approach was developed to organise the integration process in Europe (Mayhew (1998), European Commission (2001), Grabbe (2002)).

First, the so-called Europe-Agreements were negotiated with the transition countries interested in EU membership. These agreements were designed to enhance political, economic and cultural co-operation. Perhaps most importantly, a gradual and asymmetric introduction of a free trade area was included. The EU opened its borders more rapidly for the exports of the CEECs than vice versa. With the exception of agriculture, trade was practically free by the end of the 90s. In addition to regular association treaties with third countries, the EU acknowledged that the CEECs might be able to become EU members at a later stage. The first Europe-Agreements were concluded in December 1991.

Second, the EU clarified the conditions successful applicants would have to fulfil. In more general terms, this was done by the heads of state and government at the European Council of Copenhagen in June 1993. Applicants would need to accept the basic aims of a political and a monetary union. They would need to have a stable and democratic political system, a functioning market economy capable of withstanding competition pressure in the internal market and the willingness and ability to implement the acquis communautaire, i.e. the EU laws and regulations. The EU member states and the European Parliament were to decide on the individual applications. The compilation of the detailed conditions (European Commission (1995)), the monitoring of the candidates' readiness and of the actual negotiations was all 'contracted' out to a third party, the European Commission; as the war of attrition framework would recommend.

Only after this were the first applications for memberships accepted in April 1994. The Commission carried out a 'screening' of the national laws and regulations of each candidate and of their compatibility with EU law. It started to produce annual reports on the progress of the candidates preparing for membership (e.g. European Commission (2002)). Based on the results, accession negotiations started with six candidate countries in March 1998 and with the remaining countries in February 2000. Referring to the loca- 
tion of the decisive summits, the first group was christened the 'Luxembourg Group' (Poland, Hungary, Czech Republic, Slovenia, Estonia and Cyprus) and the second the 'Helsinki-Group' (Bulgaria, Romania, the Slovak Republic, Latvia, Lithuania and Malta). Turkey was acknowledged as an official candidate for membership but was considered not yet ready to start actual negotiations. Thus the EU member governments always stressed that beginning negotiations was no guarantee for their success, that each country would be judged by its individual achievements and that, therefore, the problems of any individual country would not delay the membership of more advanced candidates. This was dubbed the 'Regatta'-Model: everyone starts negotiations under the same conditions; participants in the second wave could catch up to those from the first wave or even overtake them; nobody knows who wins or whether everyone will reach the finish line; and everyone will move at his own pace.

\section{Characteristics of the negotiations}

In emphasising the importance of the implementation of the acquis communautaire by all membership candidates, the EU acted pretty much as deduced in Part 1 of the policy implications presented in Section $2 .{ }^{5}$ It accepted at an early stage that the applicants deserved membership in principle but that actual accession negotiations were not based on the idea of mutual benefits of enlargement. Enlargement was interpreted as a historical and political obligation that could generate benefits for old and new members if organised appropriately. The EU never allowed a 'give-and-take' negotiation to develop, e.g. the applicants could not obtain any permanent exception from the acquis because of any specific benefits their membership would bring for the old EU members. In establishing this position as the framework for enlargement negotiations, the existing EU members showed extreme patience and abstracted from their own benefits from enlargement (their $\alpha$ ). Hence, the applicants were responsible for the adjustment process and, therefore, for the duration of the enlargement process. This fits closely with the efficient negotiation strategy deduced in Section 2.

However, the EU did not place the financial adjustment burden solely on the shoulders of the applicants (European Commission (2001), Weise (1996)).

\footnotetext{
${ }^{5}$ Given that the EU always rejected the theoretical option of 'closing the door', i.e. of definitely blocking an applicant from membership once and for all, Part 2 of the policy implications is less relevant here (see e.g. Prodi (2002)). Nevertheless, the need to get accustomed to the new situation with 25 member states will, most certainly, delay the next enlargement round. This, however, is different from a permanent closing of the door for Bulgaria, Romania, Turkey or the western Balkans.
} 
On the contrary, it lent substantial financial and technical support to the applicants in order to enable them to implement the acquis, i.e. reducing the effective $\tau$ for the applicants. Specific payments started with some 0.4 bn. ECU in 1990 and reached $3.3 \mathrm{bn}$. euro in 2001. Initially these support payments were meant to help the transition countries in the restructuring of their economies in general. Throughout the 90s, they were more and more targeted at supporting introducing community laws and regulations.

Parallel to the accession negotiations, the EU also widened the benefits the applicants could expect from membership, i.e. increasing $\beta$. The most significant example of this is the treatment of the direct income support payments, the most important element of the Common Agricultural Policy (CAP). These were invented in the early 90 s as a compensation for a reduction in artificial price support mechanisms that became necessary due to the GATT Uruguay Round. As there were no such price supports in the candidate countries, and therefore no such reductions, the EU decided in 1999 that these compensation payments were not to be introduced in the new member states (Europen Council (1999)). This view was challenged immediately by the candidate countries and other critics because the EC Treaty prohibits unequal treatment of any economic agent solely due to his nationality. In the final stage of accession negotiations, the EU changed its position and agreed to a gradual phasing in of these subsidies in the new member states (European Council (2002)). Eventually this will mean an additional approx. $5 \mathrm{bn}$. euro per year from EU coffers for the new members.

As deduced from our model in the policy implications of Section 2, by developing this bargaining strategy, the EU member states built up a very strong position in the accession negotiations. They delegated important parts of the process to an independent third party. They displayed patience and did not set any deadline for accession. They emphasised the importance of new members implementing the acquis and refused to accept any changes to the accession criteria because of enlargement benefits to the 'old' EU. In addition, they supported the applicants in the implementation of EU law and they increased the potential benefits of membership in the course of the negotiations. The first results of the accession negotiations demonstrated the credibility and consistency of the EU approach. While the EU assumed in 1999 as a 'technical hypothesis' that the six countries of the Luxembourg Group might join in 2002 and no one else before 2007, the actual first enlargement round is now scheduled to consist of four additional countries but will take place in May 2004. This shows a credible commitment to patience on the one hand and to the 'regatta' model on the other: six countries had to wait longer than planned because they were not deemed ready soon enough, but the Slovak Republic, Latvia, Lithuania and Malta were more successful 
than envisaged in the Agenda 2000, and thus admitted sooner.

While this picture is dominated by a strong EU, we can also identify two major examples of successes of applicants in specific topics. Both fit well into our formal framework because they were achieved due to downplaying the benefits from and interest in EU membership and by exaggerating the costs of accepting the demands of the EU. The first example is related to the EU proposal to limit the free migration of labour in the initial years of membership. The candidates seized the opportunity to emphasise the high costs of accepting any deviation from the acquis in this area. Finally, they coupled the issue successfully with their demand to obtain very long transition periods before accepting the right of $\mathrm{EU}$ foreigners to own land in the applicant countries. The second example is the already mentioned topic of direct income support payments. The applicants emphasised the importance of equal treatment and substantial subsidies for their agricultural sector especially with reference to the referenda that will have to take place before the accession treaties can come into force. In effect, they successfully downplayed all other benefits of membership apart from agricultural subsidies (claiming a low $\beta$ ) and highlighted the national political costs of not getting these payments (claiming a high $\tau$ ).

\section{Limitations of the approach}

While the war of attrition model has some explanatory relevance for the actual accession negotiations, in particular with respect to a strong and successful position of the EU, there are also important limitations of the model and hence reasons for a more sceptical assessment of the EU approach.

First of all, from the point of view of smaller and/or well-advanced transition countries like Hungary or Slovenia, the equal treatment of all applicants that was implied by the 'regatta' model was never very convincing. These countries felt ready for membership relatively early and saw themselves as being forced to wait for sufficient progress of Poland (e.g. Inotai (2001)), which was for political and historical reasons the most important candidate but also caused severe problems in the accession process, partly because it is the most populous new member.

Second, from a more theoretical perspective, the assumed degree of information in our model might be problematic. On the one hand, the assumed degree of information is too low. The governments of the EU member states have to downplay benefits from enlargement vis-à-vis the applicants but they have to emphasise them vis-à-vis their own population. This makes it very difficult to maintain a consistent communication strategy. On the other hand, the assumed degree of information is too high. The actual benefits from en- 
largement are very hard to quantify. From an economic point of view, the most important aspect probably is a pro-competitive effect in the wake of closer economic integration, but this might be difficult to be viewed as a benefit by non-economists among the EU population.

Third, the EU always refused to couple enlargement with the internal reform debate. This was appropriate in order to achieve smooth accession negotiations. However, the EU risks being more poorly prepared for enlargement than the applicants, because necessary improvements in the budgetrelevant policies and institutions and the decision-making process still have not taken place (e.g. Baldwin et al. (2000), Brücker and Weise (2002), Brusis and Emmanouilidis (2002) and Siebert (2002)).

\section{Conclusion}

The paper employs a simple war of attrition framework to examine the bargaining process of EU eastward enlargement. Thus we categorise the enlargement bargaining process as a waiting game. Both players - the current EU members and the applicants - benefit from enlargement, yet for the applicants, reform according to the acquis is costly, while the EU prefers to admit substantially reformed candidates.

Within this formal framework, we study and explain a number of bargaining strategies and episodes that have been observed during the past ten years of negotiations. First, the strategy of out-sourceing the formal evaluation of the candidates' reform status (i.e. the Copenhagen Criteria) to the Commission is, within the bargaining framework presented here, a useful strategy for the current EU members, and produces a clear bargaining advantage. Second, to evaluate the progress of each country individually without closing the door is, within our framework, a sensible strategy for the existing EU members. Third, compensating the applicant countries for their reform efforts again strengthens the current EU members' negotiation positions. Fourth, increasing the benefits to the applicants as well as, fifth, excluding the option of changing the acquis in the negotiations again strengthens the bargaining position of the existing members. Finally, these reasonings also apply the other way around. In particular, applicant countries where the public's enthusiasm for EU-membership is declining will - within the formal framework - be able to enter on more favorable (weaker reform) terms. Similarly, exaggerating the costs that the required reforms cause, and downplaying the benefits of a membership are efficient negotiation strategies. Applicants have indeed strengthened their position in the negotiations by downplaying their benefits and their interest in EU membership and by exaggerating the costs 
of complying with certain EU demands, i.e. in the field of the CAP. 


\section{A Appendix}

\section{A.1 Derivatives in Proposition 1}

Derivatives of the EU's maximum waiting time. Differentiating $\bar{t}_{E}$ given in (2) in the main text with respect to $\alpha, \sigma$ and $\rho_{E}$ gives:

$$
\frac{\partial \bar{t}_{E}}{\partial \alpha}=\frac{\sigma}{\alpha(\alpha-\sigma)} \log \left(\frac{1-\phi}{1+\rho_{E}}\right)^{-1}
$$

which is negative, since the first term is positive and the second term is negative $\left(\frac{1-\phi}{1+\rho_{E}}<1\right)$. Hence, $\frac{\partial \bar{t}_{E}}{\partial \alpha}<0$. Further,

$$
\frac{\partial \bar{t}_{E}}{\partial \sigma}=\frac{-1}{(\alpha-\sigma)} \log \left(\frac{1-\phi}{1+\rho_{E}}\right)^{-1}
$$

which is positive, since both the first term and the second term are negative. Hence, $\frac{\partial t_{E}}{\partial \sigma}>0$. Finally,

$$
\frac{\partial \bar{t}_{E}}{\partial \rho_{E}}=\frac{\log \left(\frac{\alpha-\sigma}{\alpha}\right)}{\left(1+\rho_{E}\right) \log \left(\frac{1-\phi}{1+\rho_{E}}\right)^{2}}
$$

which is negative, since the numerator is negative $\left(\frac{\alpha-\sigma}{\alpha}<1\right)$, while the denominator is positive. Hence, $\frac{\partial \bar{t}_{E}}{\partial \rho_{E}}<0$.

\section{A.2 Derivatives in Proposition 2}

Fully parallel to Appendix A.1 the derivatives of the applicant's maximum waiting time can be stated. Differentiating $\bar{t}_{A}$ given in (4) in the main text with respect to $\beta, \tau$ and $\rho_{A}$ gives:

$$
\frac{\partial \bar{t}_{A}}{\partial \beta}=\frac{\tau}{\beta(\beta-\tau)} \log \left(\frac{1-\phi}{1+\rho_{A}}\right)^{-1}
$$

which is negative, since the first term is positive and the second term is negative $\left(\frac{1-\phi}{1+\rho_{A}}<1\right)$. Hence, $\frac{\partial \bar{t}_{A}}{\partial \beta}<0$. Further,

$$
\frac{\partial \bar{t}_{A}}{\partial \tau}=\frac{-1}{(\beta-\tau)} \log \left(\frac{1-\phi}{1+\rho_{A}}\right)^{-1}
$$

which is positive, since both the first term and the second term are negative. Hence, $\frac{\partial \bar{t}_{A}}{\partial \tau}>0$. Finally,

$$
\frac{\partial \bar{t}_{A}}{\partial \rho_{A}}=\frac{\log \left(\frac{\beta-\tau}{\beta}\right)}{\left(1+\rho_{A}\right) \log \left(\frac{1-\phi}{1+\rho_{A}}\right)^{2}}
$$


which is negative, since the numerator is negative $\left(\frac{\beta-\tau}{\beta}<1\right)$, while the denominator is positive. Hence, $\frac{\partial \bar{t}_{A}}{\partial \rho_{A}}<0$.

\section{A.3 Proposition 3}

Differentiating $f$ given in (5) in the main text with respect to the closing the door probability $\phi$ gives:

$$
\frac{\partial f}{\partial \phi}=\frac{\log \left(\frac{\alpha-\sigma}{\alpha}\right)}{(1-\phi) \log \left(\frac{1-\phi}{1+\rho_{E}}\right)^{2}}-\frac{\log \left(\frac{\beta-\tau}{\beta}\right)}{(1-\phi) \log \left(\frac{1-\phi}{1+\rho_{A}}\right)^{2}}
$$

Setting $\rho_{E}=\rho_{A}=\rho$ the sign of the derivative depends on the numerators in the two terms. Rewriting gives:

$$
\frac{\frac{\partial f}{\partial \phi}}{\left|\frac{\partial f}{\partial \phi}\right|}=\frac{\frac{\beta}{\beta-\tau}-\frac{\alpha}{\alpha-\sigma}}{\left|\frac{\beta}{\beta-\tau}-\frac{\alpha}{\alpha-\sigma}\right|}
$$

Hence, $\frac{\partial f}{\partial \phi}>0$ if $\frac{\beta}{\beta-\tau}>\frac{\alpha}{\alpha-\sigma}$; and $\frac{\partial f}{\partial \phi}<0$ if $\frac{\beta}{\beta-\tau}<\frac{\alpha}{\alpha-\sigma}$. 


\section{References}

Alesina, A., A. Drazen (1991), Why are Stabilisations Delayed?, American Economic Review, Vol. 81 (5), pp. 1170-1188.

Baldwin, R. E., J. F. Francois, R. Portes (1997), The Costs and Benefits of Eastern Enlargement: The Impact on the EU and Central Europe, Economic Policy, Vol. 24, pp. 127-170.

Baldwin, R. E., E. Berglöf, F. Giavazzi, M. Widgrén (2000), EU Reforms for tomorrow's Europe, CEPR Discussion Paper No. 2623, London.

Bliss, C., B. Nalebuff (1984), Dragon-slaying and ballroom dancing: The private supply of a public good, Journal of Public Economics, Vol. 25, pp. $1-12$.

Boeri, T., H. Brücker et al. (2000), The Impact of Eastern Enlargement on Employment and Labour Markets in the EU Member States, Report for the DG Employment of the European Commission, European Integration Consortium (DIW, CEPR, FIEF, IAS, IGIER), Berlin/Milan.

Breuss, F. (1999), Costs and Benefits of EU Enlargement in Model Simulations, IEF Working Papers No. 33, Vienna.

Brücker, H., C. Weise (2002), The EU on the Eve of Enlargement: The European Convention should seize the opportunity to introduce reforms, Economic Bulletin, No. 12 Vol. 11. 
Brusis, M., J. Emmanouilidis (eds.) (2002), Thinking Enlarged - The Accession Countries and the Future of the European Union, Bonn.

European Commission (1995), Preparation of the associated countries of Central and Eastern Europe for the integration into the Single Market of the Union, White Paper, COM (95) 163 final, Brussels.

European Commission (2001), Enlargement of the European Union - An historic opportunity, Brussels.

European Commission (2002), Towards the enlarged Union - strategy paper and report of the European Commission on the progress towards accession by each of the candidate countries, COM (2002) 700 final, Brussels.

European Council (1999), European Council (Berlin), Presidency Conclusions. 24 and 25 March 1999.

European Council (2002), European Council (Brussels), Presidency Conclusions, 24 and 25 October 2002.

Grabbe, H. (2001), How does Europeanization affect CEE governance? Conditionality, diffusion and diversity, Journal of European Public Policy, Vol. 8, No. 6, pp. 1013-1031.

Grabbe, H. (2002), European Union conditionality and the Acquis communautaire, International Political Science Review, Vol. 23(3), pp. 249-268.

Heinemann, F. (2000), Strategic Lessons from the Maastricht Criteria, Kredit und Kapital, Vol. 33(4), pp. 455-467. 
Hendricks, K., A. Weiss, C. Wilson (1988), The war of attrition in continuous time with complete information, International Economic Review, Vol. 29, pp 663-680.

Inotai, A. (2001), Some Reflections on possible scenarios for EU enlargement/Some key issues in understanding the negotiations on accession to the European Union, Institute for World Economics, Working Papers No. 122, Budapest.

Josling, T., D. Kelch, P. Liapis, S. Tangermann (1998), Agriculture and European Union Enlargement. Market and Trade Economics Division, Economic Research Service, U.S. Department of Agriculture. Technical Bulletin No. 1865. Washington, D.C.

Kohler, W. (2000), Wer gewinnt, wer verliert durch die Osterweiterung der EU? In: Erweiterung der EU, Jahrestagung 1999, hrsg. von Lutz Hoffmann, Schriften des Vereins für Socialpolitik Band 274, Duncker Humblot, Berlin, pp. $27-78$.

Mattli, W., T. Plumper (2002), The demand-side of EU enlargement: democracy and the application for EU membership, Journal of European Public Policy, Vol. 9, No. 4, pp. 550-574.

Mayhew, A. (1998), Recreating Europe: The European Union's Policy towards central and eastern Europe, Cambridge University Press.

Mayhew, A. (2000), Enlargement of the European Union: An Analysis of the Negotiations with the Central and Eastern European Candidate Countries, 
Sussex European Institute Working Paper No. 39.

Perotti, E. (1998), Inertial credit and opportunistic arrears in transition, European Economic Review, Vol. 42, pp. 1703-1725.

Prodi, R. (2002), One Europe, Speech delivered to the European Parliament, 18 December 2002.

Schimmelfennig, F., U. Sedelmeier (2002), Theorizing EU enlargement: research focus, hypotheses, and the state of research, Journal of European Public Policy, Vol. 9, No. 4, pp. 500-528.

Siebert, H. (2002), Europe - Quo Vadis? Reflections on the Future Institutional Framework of the European Union, The World Economy, Vol. 25, No. 1, pp. 1-32.

Tangermann, S., M. Banse (Eds.) (2000), Central and Eastern European Agriculture in an Expanding European Union, Wallingford, New York.

Weise, C. (1996), From Association to Membership: What can be done by the EU to ease Eastern Enlargement? Vierteljahrshefte zur Wirtschaftsforschung 3/1996, Special Issue: European Integration, pp. 309-322.

Weise, C., J. Bachtler, R. Downes, I. McMaster, K. Toepel (2001), The Impact of EU Enlargement on Cohesion - Background Report for the Second Report on Economic and Social Cohesion of the European Commission, Study for DG Regio, Berlin and Glasgow. 